\title{
The Role of Pure Tissue Repair of Inguinal Hernia in Middle Aged Males in the Present Time
}

\author{
Mohammed Alabed Alhamid* \\ Department of General Surgery, King Fahad Hospital, Albaha, Saudi Arabia
}

Received: May 23, 2019; Published: June 17, 2019

*Corresponding author: Mohammed Alabed Alhamid, Department of General Surgery, King Fahad Hospital, Albaha, Saudi Arabia

\begin{abstract}
Objective: Inguinal hernia is one of the most commonly encountered problem in surgical practice. The different repair techniques were performed for a long time. The Lichtenstein herniorrhaphy as a tension-free method, has gained popularity in last years. This work aimed to demonstrate the results of inguinal hernia repair in middle aged males with different surgical techniques.
\end{abstract}

Materials and Methods: A series of 100 middle aged male patients presented with primary uncomplicated inguinal hernia. Three different surgical techniques (modified Bassini, Shouldice, and Lichtenstein) were performed for inguinal hernia. The patient's age, operation details, early and late complications, duration of hospital stay, occurrence of chronic pain and recurrence rates were collected.

Results: There were 100 middle aged males in this study. The mean age was 36.4 (range 20-40) years. The performed surgical techniques were Shouldice repair (16 patients), modified Bassini (58 patients), and Lichtenstein technique (26 patients). The shortest operation time was detected in modified Bassini repair. The most common early complication was scrotal edema. There were 1 (1\%) recurrence in Bassini repair and 1 recurrence $(1 \%)$ in Shouldice repair.

Conclusion: Seventy-four patients (74\%) treated with pure tissue repair in the present series. Shouldice, modified Bassini, and Lichtenstein repairs seem to have similar results in terms of postoperative complication and recurrence rates in repair of middle-aged males with unilateral primary uncomplicated inguinal hernia.

Keywords: Inguinal Hernia Repair; Modified Bassini; Shouldice Repair; Lichtenstein Repair; Postoperative Complications

\section{Introduction}

Groin hernia repair is one of the most commonly performed operations by general surgeons. Approximately $75 \%$ of all abdominal wall hernias are seen in the groin [1]. Inguinal hernia is much more common in men than women. Although umbilical and femoral hernias are more common in females, indirect inguinal hernia is still a significant type of hernia in women [2]. Age is a factor, as incidence increases by age [3]. Indirect hernia is more common in young patients and direct hernia in the elderly.

It is proposed that more than 20 million of inguinal hernia repairs are performed worldwide every year. Recurrence after primary repair will add an extra cost to health care economics. A secondary or even tertiary operations after previous repairs carry higher risk of re-recurrence and specific complications as testicular atrophy. Every surgeon should perform a current repair method successfully in his daily practice [4].

Inguinal hernia is a very common problem. Surgical repair is the current approach, whereas asymptomatic or minimally symptomatic hernias may be good candidate for watchful waiting.
Prophylactic antibiotics can be used in centers with high rate of wound infection. Spinal anesthesia is a suitable and economic option for open repairs and should be popularized in day-case setting. Numerous repair methods have been described to date. Mesh repairs are superior to "non-mesh" tissue-suture repairs. Lichtenstein repair and endoscopic/laparoscopic techniques have similar efficacy. Standard polypropylene mesh is still the choice, whereas use of partially absorbable lightweight meshes seems to have some advantages [5].

Many repair techniques have been described, however tension-free mesh repair is widely used method nowadays because of its low recurrence rate. Pure tissue repair in certain situation has several advantages including: it is an effective operation performed as an outpatient procedure with low morbidity and mortality, it is more economic, safe with low complications rate, and it has a reduced short- and long-term recurrence rate. Mesh repair has a multiple disadvantage that including time consuming, risk of injury from excessive dissection, costly, infection, pain, recurrence, rejection, migration, fold and wrinkle [6]. 
Irfan et al. operated upon 210 hernia patients; they found the recurrence rate of modified Bassini repair to be less than $0.7 \%$ [7]. Pinter and Markus in their study of 343 hernia repairs by Shouldice method have reported a recurrence rate as low as $0.9 \%$ [8]. A recent meta-analysis by Parviz et al., showed recurrence rates of $0-0.7 \%$ after Lichtenstein repair both by surgeons with special interest in hernia surgery [9].The aim of this study was to compare the outcome following different methods of inguinal hernia repair in middle aged males with unilateral primary uncomplicated inguinal hernia.

\section{Patients and Methods}

The present study based on 100 selected cases of unilateral, primary, uncomplicated inguinal hernia in young adult males (From 20-40 years). Bilateral, recurrent, femoral, strangulated or incarcerated hernias were excluded from the study. All patients were exposed to carful history taking, proper general and local examination, and investigated pre-operatively on outpatient bases for planned surgery. All patients were admitted the day before surgery. Operations were done under spinal anesthesia. All patients in the present series received preoperative antibiotic. The choice of operative technique depended on integrity of the posterior wall and the condition of the local inguinal tissues.

The upper flap of the wound dissected to reveal upper flap of external oblique, conjoint muscle/tendon, lower arching fibers of transversus abdominis, and upper flap of fascia transversalis. The lower flap of the wound dissected to reveal lower flap of external oblique, inguinal ligament, and iliopubic tract (lower flap of fascia transversalis). Thus, four structures formed the upper flap, and three structures formed the lower flap. The integrated and well-formed flaps was used in pure tissue repair without undue tension (the name of the repair depends on the chosen flaps). If most or all flaps are ill- formed, weak, or may be approximated under tension mesh was used for repair. The different techniques used were:

\section{Shouldice Repair}

The transversalis fascia incised from internal ring to the pubic tubercle parallel to the inguinal ligament. Multilayer repair is done. First layer of repair is done by suturing the lower lateral flap to the deep surface of upper medial flap. The lower edge of the upper flap of transversalis fascia is sutured to the base of the lower edge of the lower flap of transversalis fascia as the second layer. Third layer sutured inguinal ligament to the aponeurotic tendon of the transverses abdominis. Fourth layer started from the anterior rectus sheath and the lower aspect of the conjoined tendon to the inner surface of the lower flap of the external oblique aponeurosis. The cord is now laid on the fourth layer and the external oblique aponeurosis closed in front of cord in two layers.

\section{Modified Bassini's Repair}

In this method, the conjoined tendon is sutured to the margin of inguinal ligament by polypropylene material. The first suture passes through the periosteum of pubic tubercle. Stiches are taken at different level over the inguinal ligament.

\section{Lichtenstein Tension-Free Repair}

In this repair a sheet of partially absorbable lightweight polypropylene mesh used to reconstruct the entire floor of the inguinal canal without any attempt to close the defect by suture. The mesh is sutured along its lower edge to the pubic tubercle, lacunar ligament and the inguinal ligament beyond the internal ring with a continuous suture of polypropylene. The medial edge of mesh is sutured to the rectus sheath, also with polypropylene continuous suture. The superior edge is fixed with few interrupted sutures to the aponeurotic part of internal oblique muscle or undersurface of external oblique aponeurosis. The lateral edge of mesh is slit, and the two tails passed around to embrace the cord at the internal ring, then they are crossed over each other and sutured with each other by polypropylene. This creates a new internal ring and shutter mechanism.

Patients were followed up at regular intervals up to one year. They were examined for complications, recurrences. All patients were advised not to do any strenuous work for 3 months.

\section{Statistical Analysis}

All statistical data will be analyzed using SPSS 11.0. Descriptive statistics i.e. mean + SD for numerical data and percentages for nominal data will be used to describe the data.

\section{Results}

Inguinal hernia is major surgical issue. The different techniques used for repair of inguinal hernia accounts for various advantages of one method over the other. Thus, it seems to be mandatory to evaluate and compare the end results of various techniques of hernia repair.

Table 1: Patients distribution according to age.

\begin{tabular}{|c|c|c|}
\hline Age (years) & Number of patients & \% \\
\hline$\geq 20-<25$ & 10 & $10 \%$ \\
\hline$\geq 25-<30$ & 17 & $17 \%$ \\
\hline$\geq 30-<35$ & 47 & $47 \%$ \\
\hline$\geq 35-40$ & 26 & $26 \%$ \\
\hline Total & 100 & $100 \%$ \\
\hline
\end{tabular}

Table 2: Type of repair.

\begin{tabular}{|c|c|c|c|}
\hline Repair & $\begin{array}{c}\text { Shouldice } \\
\text { Technique }\end{array}$ & $\begin{array}{c}\text { Modified Bassini } \\
\text { Technique }\end{array}$ & $\begin{array}{c}\text { Lichtenstein Tension- } \\
\text { Free Mesh Technique }\end{array}$ \\
\hline Total & $16(16 \%)$ & $58(58 \%)$ & $26(26 \%)$ \\
\hline
\end{tabular}

In the present study, comparison of inguinal hernia repair by Shouldice versus modified Bassini's repair, and Lichtenstein tension-free repair had been studied with a regular follow up. All patients were between 20-40 years (Table 1). Out of the 100 patients, Shouldice repair was done in 16 patients, modified Bassini was done in 58 patients and Lichtenstein tension-free repair was done in 26 patients (Table 2). In the present study, direct inguinal hernia was commoner in older age group while 


\section{Open Access Journal of Surgery}

indirect inguinal hernia was commoner in younger patients which can be comparable with other studies. Out of 100 cases, $84 \%$ had indirect hernia, and 16\% had direct hernia. $61 \%$ of the patients had right sided hernias (Table 3). All patients underwent surgery under spinal anesthesia.

Table 3: Side and type of inguinal hernia and the technique used to repair it.

\begin{tabular}{|c|c|c|c|c|c|c|}
\hline \multicolumn{2}{|c|}{ Hernia } & \multirow{3}{*}{$\begin{array}{c}\text { Shouldice } \\
\text { Technique }\end{array}$} & \multirow{3}{*}{$\begin{array}{c}\begin{array}{c}\text { Modified Bassini } \\
\text { Technique }\end{array} \\
3 \\
\end{array}$} & \multirow{3}{*}{$\begin{array}{c}\text { Lichtenstein Tension-Free Mesh } \\
\text { Technique }\end{array}$} & \multirow{2}{*}{\multicolumn{2}{|c|}{ Total }} \\
\hline Site & Type & & & & & \\
\hline \multirow{2}{*}{ Right } & Direct & & & & 12 & \multirow{2}{*}{$61(61 \%)$} \\
\hline & Indirect & 10 & 29 & 10 & 49 & \\
\hline \multirow{2}{*}{ Left } & Direct & 1 & 1 & 2 & 4 & \multirow{2}{*}{$39(39 \%)$} \\
\hline & Indirect & 4 & 25 & 6 & 35 & \\
\hline \multicolumn{2}{|c|}{ Total } & $16(16 \%)$ & $58(58 \%)$ & $26(26 \%)$ & \multicolumn{2}{|c|}{$100(100 \%)$} \\
\hline
\end{tabular}

Table 4: Mean hospital stay.

\begin{tabular}{|c|c|c|c|}
\hline Hospital Stay (hours) & Shouldice Technique & Modified Bassini technique & Lichtenstein Tension-Free Mesh Technique \\
\hline Range & $1-3$ days & $1-2$ days & $1-2$ days \\
\hline Mean & 1.75 days & 1.17 days & 1.4 days \\
\hline
\end{tabular}

The mean hospital stay was 1.75 days (1-3 days) in Shouldice technique group, 1.17 days (1-2 days) in modified Bassini technique and 1.4 days (1-2 days) in Lichtenstein tensionfree mesh technique group (Table 4). In present study, wound hematoma occurred in two patients, which may be attributed to extensive dissection. Two patients developed seroma of Table 5: Early post-operative complications.

\begin{tabular}{|c|c|c|c|c|}
\hline Complication & Shouldice Technique & Modified Bassini Technique & $\begin{array}{c}\text { Lichtenstein tension-free mesh } \\
\text { Technique }\end{array}$ & Total \\
\hline Hematoma & 0 & 1 & 1 & 2 \\
\hline Seroma & 0 & 1 & 1 & 2 \\
\hline Superficial infection & 1 & 2 & 3 & 1 \\
\hline Scrotal swelling & 1 & 8 & 1 & 3 \\
\hline Retention of urine & 1 & 1 & 26 patients & 100 patients \\
\hline Total & 16 patients & 58 patients & 1 & \\
\hline
\end{tabular}

As regards to late post-operative complications (up to one year), neuralgia was the commonest (5 patients, $5 \%$ ). It was most common and statistically significant in modified Bassini technique group $(3 / 5,60 \%)$. Scar problems occurred in 4 patients (4\%). It was most common and statistically significant Table 6: Late post-operative complications (after 1 year).

\begin{tabular}{|c|c|c|c|c|}
\hline Late Complications & Shouldice Technique & Modified Bassini Technique & $\begin{array}{c}\text { Lichtenstein Tension-Free Mesh } \\
\text { Technique }\end{array}$ & Total \\
\hline Neuralgia & 1 & 3 & 1 & 5 \\
\hline Scar problems & 1 & 2 & 0 & 4 \\
\hline Recurrence & 1 & 1 & 32 patients & 100 patients \\
\hline Total & 12 patients & 48 patients
\end{tabular}

\section{Discussion}

Numerous techniques of repair of inguinal hernia were described since Eduardo Bassini (the pioneer of modern inguinal hernia repair) had published his first anatomical- based repair with unique success in 1890. During the 20th century, the repair trend was changed several times. Although Shouldice Hospital achieves a very low cumulative recurrence rate by performing the wound respond to aspiration. Four patients developed superficial wound infection, treated by antibiotics and dressing. Twelve patients developed scrotal edema, which is treated by scrotal support and anti-inflammatory agents. Three patients developed urinary retention, relieved by catheterization (Table $5)$.

in modified Bassini technique group $(2 / 4,50 \%)$. In the present study, two cases of recurrences (2\%) were encountered. As the follow up time was short (for one year only), recurrence rate after 5 years may be estimated in another article (Table 6). its own tissue suture technique [10], today prosthetic repairs are superior to "non-mesh" suture repairs. Delikoukos et al. [11] in a recent meta-analysis concluded that Shouldice herniorrhaphy is considered to be the best non-mesh technique in terms of recurrence, though it is more time consuming and needs a slightly longer post- operative hospital stay. Nevertheless, the use of mesh is associated with a lower rate of recurrence. 
Transversalis fascia is often quite strong in young patients and indirect hernias can be treated without a mesh [12].

Today, some strong recommendations exist in favor of Lichtenstein hernioplasty. American College of Surgeons choose this technique as the "gold standard" [13]. National Institute of Clinical Excellence (NICE) from United Kingdom [14], and National Agency for Accreditation and Evaluation in Health (ANAES) from France [15], recommended it for inguinal hernia repair. It is easy to learn and perform. Reasonable recurrence and complications rates have been obtained worldwide [15].

A hernia mesh has certain features like material, strength, elasticity, density, and pore size. Standard polypropylene mesh is most frequently used one. It is cheap, available in most hospitals, non-absorbable, and its tensile strength is strong enough to avoid recurrence. Nevertheless, some annoying morbidities with mesh hernioplasty like feeling of foreign body at the site of surgery and chronic postoperative pain have created a conflict about standard polypropylene mesh. Polyester mesh might be an alternative prosthesis, but it does not gain popularity, as it can degrade by time especially in infected areas [16].

Newer lighter meshes have been produced to overcome those problems [17] Nevertheless, lightweight meshes (28-30gram polypropylene/m2) are more expensive than standard polypropylene mesh (>90-gram polypropylene/m2). Mere polypropylene light-weight mesh is one of the most economic options. There are also armored polypropylene meshes in the market. The aim from coating polypropylene fibers is to attenuate the host response to the prosthetic, yet still provide adequate strength for repair. Fish oil, beta glucan and titanium have been used for coating [18].

Partially absorbable meshes have two components. Polypropylene non absorbable part does not lose its strength at all. The other half is absorbed within 12 weeks [19]. Eventually less foreign material is left in situ, while the remaining mesh can still provide a sufficient mechanical barrier against recurrence. Two controlled studies compared heavy-weight polypropylene mesh with a partially absorbable mesh in Lichtenstein repair revealed no differences [20,21]. A single- surgeon study also reported no differences between standard heavy-weight polypropylene, lightweight pure polypropylene and partially absorbable meshes [22]. Also, a recent meta- analysis study found no differences. However, use of partially absorbable light meshes could be associated with reduced feeling of a foreign body [23].

Lately a specific problem has been introduced for mesh repairs. Mesh may cause male infertility due to constriction of the vas deference [24]. Some authors have even proposed that young male patients who will undergo inguinal hernioplasty using polypropylene mesh need to cryopreserve their sperm for future fertility [25]. On the contrary, Aydede et al. reported that application of mesh is a safe procedure in males with no children or who receive infertility treatment [26]. A very recent study from Sweden also has shown that patients undergo synchronous bilateral inguinal hernioplasty are not at greater risk of male infertility rate than those operated with herniorrhaphy [27].

Bruising, seroma, and hematoma formation are relatively common following inguinal hernia repair. In Fitzgibbons et al. trial, 6.1 percent of patients undergoing open, mesh repair developed a wound hematoma, 4.5 percent developed a scrotal hematoma, and 1.6 percent developed a serum [28]. Seromas and hematomas are reported in about 5 percent of laparoscopic hernia repairs [29]. These results are comparable to that of the present study.

Persistent groin pain and post-herniorrhaphy neuralgia is common. Some form of chronic or residual postoperative discomfort/pain is present after inguinal hernia repair with reported rates ranging from $0.7 \%$ to $43.3 \%$. The exact nature of pain can vary over time. Pain complicating hernia surgery should diminish and disappear within an expected time interval, but when it persists for more than three months and is proved not to be related to other possible causes, a presumptive diagnosis of post-herniorrhaphy neuralgia can be made. In the present study neuralgia occurred in 5 patients (5\%). It was most common and statistically significant in modified Bassini technique group $(3 / 5$, $60 \%)$. Scar tenderness occurred in 4 patients (4\%). It was most common and statistically significant also in modified Bassini technique group $(2 / 4,50 \%)$. These figures are comparable with other series.

In the present study, two cases of recurrences (2\%) were encountered. One in Shouldice repair and one in modified Bassini technique. This represents $2 \%$ of all groups which is comparable to other series. There was no statistically significant difference between the three groups as regard to recurrence. After one year of follow up none of the patients developed any symptoms or manifestations suggesting deep wound infection or mesh graft infection, rejection, or migration. The absence of risk factors as, morbid obesity, diabetes, renal and hepatic impairment, glucocorticoid use, prior hernia surgery, and mesh repair of complicated hernia contribute to the absence of such complications. The use of light-weight polypropylene mesh and usage of prophylactic antibiotics may be another contributing factor.

\section{Conclusion}

Although Lichtenstein's and laparoscopic hernioplasty of the inguinal hernia are the gold standard techniques, tissue repair (herniorrhaphy) procedures still held good. Proper understanding of the pathophysiology of inguinal hernia and anatomical bases of perfect tissue repair are mandatory in successful herniorrhaphy. Tissue repair is not a primitive method that is to be avoided; rather, it has comparable results with hernioplasty. Tissue repairs hold good even today in the deserving patients, and selected settings when undertaken 
without hesitation where necessary. Shouldice and modified Bassini techniques still have very important place in the repair of primary uncomplicated inguinal hernia in middle aged males. Early and late postoperative complications are minimal and comparable to that of mesh repair including recurrence rate.

\section{References}

1. Kulacoglu H (2011) Current options in inguinal hernia repair in adult patients. Hippokratia. 15(3): 223-231.

2. Koch A, Edwards A, Haapaniemi S (2005) Prospective evaluation of 6895 groin hernia repairs in women. Br J Surg 92(12): 1553-1558.

3. Akinci M, Ergül Z, Kulah B, Yilmaz KB, Kulacoglu H (2010) Risk factors related with unfavorable outcomes in groin hernia repairs. Hernia 14(5): 489-493.

4. Paajanen H, Varjo R (2010) Ten-year audit of Lichtenstein hernioplasty under local anaesthesia performed by surgical residents. BMC Surg 10: 24.

5. Anand A, Sinha P, Kittappa K, Mulchandani M, Debrah S, et al. (2011) Review of Inguinal Hernia Repairs by Various Surgical Techniques in a District General Hospital in the UK. Indian J Surg 73(1): 13-18.

6. Gao M, Han J, Tian J, Yang K (2010) Vypro II mesh for inguinal hernia repair: a meta-analysis of randomized controlled trials. Ann Surg 251(5): 838-842.

7. Irfan S, Saeed Z, Javed M, Ali W, Nasir A (2006) A Tertiary Care Hospital Experience of Efficacy of Darn Repair Versus Bassini Repair in Inguinal Hernia. RMJ 31(2): 67-69.

8. Pinter G, Markus B (2004) The place of Shouldice operation in inguinal hernia repair. Zentralbl Chir 129(2): 96-8.

9. Amid PK, Alex G, Shulman AG, Lichtenstein I (1996) Open "Tension Free" repair of inguinal hernia; the Lichtenstein Technique. Eur J Surg 162(6): 447-453.

10. Shin D, Lipshultz LI, Goldstein M, Barme GA, Fuchs EF, et al. (2005) Herniorrhaphy with polypropylene mesh causing inguinal vasal obstruction: a preventable cause of obstructive azoospermia. Ann Surg 241(4): 553-558.

11. Delikoukos S, Tzovaras G, Liakou P, Mantzos F, Hatzitheofilou C (2007) Late-onset deep mesh infection after inguinal hernia repair. Hernia 11(1): 15-17.

12. Moon V, Chaudry GA, Choy C, Ferzli GS (2004) Mesh infection in the era of laparoscopy. J Laparoendosc Adv Surg Tech A 14(6): 349-352.

13. Bisgaard T, Bay-Nielsen M, Kehlet $H$ (2008) Re-recurrence after operation for recurrent inguinal hernia. A nationwide 8-year follow-up study on the role of type of repair. Ann Surg 247(4): 707-711.

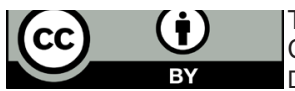

This work is licensed under Creative Commons Attribution 4.0 Licens DOI: 10.19080/OAJS.2019.10.555794
14. Jenkins JT, O Dwyer PJ (2008) Inguinal hernias. BMJ 2 336: 269-272.

15. Earle DB, Mark LA (2008) Prosthetic material in inguinal hernia repair: how do I choose? Surg Clin North Am 88(1): 179- 201.

16. Shah BC, Goede MR, Bayer R, Buettner SL, Putney SJ, et al. (2009) Does type of mesh used have an impact on outcomes in laparoscopic inguinal hernia? Am J Surg 198(6): 759-64.

17. Cobb WS, Kercher KW, Heniford BT (2005) The argument for lightweight polypropylene mesh in hernia repair. Surg Innov 12(1): 63-9.

19. Rosch R, Junge K, Quester R, Klinge U, Klosterhalfen B, et al. (2003) Vypro II mesh in hernia repair: impact of polyglactin on long-term incorporation in rats. Eur Surg Res 35(5): 445-50.

20. Bringman, Wollert, Osterberg J, Smedberg, Granlund H, et al. (2005) One-year results of a randomised controlled multi-centre study comparing Prolene and Vypro Il-mesh in Liehtenstein hernioplasty. Hernia 9(3): 223-227.

21. Puecio F, Solazzo M, Marciano P (2005) Comparison of three different mesh materials in tension-free inguinal hernia repair: prolene versus Vypro versus surgisis. Int Surg 90(3): 21-3.

22. Paajanen H (2007) A single-surgeon randomized trial comparing three composite meshes on chronic pain after Liebtenstein hernia repair in local anesthesia. Hernia 11(4): 335- 339.

23. Protasov AV, Krivtsov GA, Mikhaleva LM, Tabuika AV, Shukhtin NTu (2010) [Effects of inguinal hemioplasty mesh implant on reproductive function]. Khirurgiia (Mosk) 8: 28-32.

24. Ansaloni E, Catcna F, Coccolini F, Gazzotti F, D'Alcssandro E, et al. (2009) Inguinal hcmia repair with porcine small intestine submucosa: 3-year follow-up results of a randomized controlled trial of Lichtcnstcin's repair with polypropylene mesh versus Surgisis Inguinal Hcmia Matrix. Am J Surg 198: 303-312.

25. Aydede H, Erhan Y, Sakarya A, Kara E, Ilkgül O, Can M (2003) Effect of mesh and its localisation on testicular flow and spermatogenesis in patients with groin hernia. Acta Chir Belg 103(6): 607-610.

26. Hallen M, Sandblom G, Nordin P, Gunnarsson U, Kvist U, et al. (2011) Male infertility after mesh hcmia repair: A prospective study. Surgery 149(2): 179-184.

27. Fitzgibbons RJ Jr, Giobbie-Hurder A, Gibbs JO, Dunlop DD, Reda DJ et al. (2006) Watchful waiting vs repair of inguinal hernia in minimally symptomatic men: a randomized clinical trial. JAMA 295(3): 285-292.

28. Hawn MT, Itani KM, Giobbie-Hurder A, McCarthy M Jr, Jonasson O, et al. (2006) Patient-reported outcomes after inguinal herniorrhaphy. Surgery 140(2): 198-205.

29. Gofeld M, Christakis M (2006) Sonographically guided ilioinguinal nerve block. J Ultrasound Med 25(12): 1571-5.

\begin{tabular}{l} 
Your next submission with Juniper Publishers \\
will reach you the below assets \\
- Quality Editorial service \\
- Swift Peer Review \\
- Reprints availability \\
- E-prints Service \\
- Manuscript Podcast for convenient understanding \\
- Global attainment f or your research \\
- Manuscript accessibility in different formats \\
( Pdf, E-pub, Full Text, Audio) \\
- Unceasing customer service \\
Track the below URL for one-step submission \\
https://juniperpublishers.com/online-submission.php \\
\hline
\end{tabular}

